\title{
A Critical Review of Selye's Stress Theory: The Statistical Analyses of Selye's Own Experimental Data Disprove It
}

\author{
Yasuhiro Nageishi \\ Graduate School of Information Science, Nagoya University, Nagoya, Japan \\ Email: ynageishi@ares.eonet.ne.jp
}

Received 9 September 2015; accepted 2 November 2015; published 5 November 2015

Copyright (C) 2015 by author and Scientific Research Publishing Inc.

This work is licensed under the Creative Commons Attribution International License (CC BY).

http://creativecommons.org/licenses/by/4.0/

(c) (i) Open Access

\section{Abstract}

Selye's article (Selye, 1936a) published in "Nature" has been enormously cited and markedly affected the entire field of "stress", until today. The key concept of Selye's stress theory was "the principle of nonspecificity". Selye defined stress as the nonspecific responses of the body to various noxious agents. He gave various noxious stimuli to rats, and reported the results in his paper (Selye, 1936b). However, he described only raw data (thymus, and adrenal weights in individual rats), without even the mean values. This study analyzed those data statistically. Among his data, the result pattern most frequently observed was the both occurrences of thymus involution and adrenal enlargement. It appeared to give a conclusive evidence for Selye's theory. However, there were also other two result patterns. The second pattern was a significant decrease in the thymus weight without changes in the adrenal weight (fasting for 24 - 96 hours in 3-month-old rats, morphine injections, and skin lesions). The third pattern was no change in either the thymus or adrenal weight (exposure to heat and bone fractures). These results disproved Selye's theory of nonspecificity and they forsook it. And moreover, it was suggested that Selye's results themselves supported Mason's proposal that all stress responses were elicited through psychological emotional reactions (Mason, 1971), which were very compatible with the recent psychological stress theories.

\section{Keywords}

Selye, Stress Theory, Nonspecificity 


\section{Introduction}

Selye's article (Selye, 1936a) published in "Nature” has been enormously cited and markedly affected the entire field of "stress", until today. His stress theory has been commonly accepted, stimulating research, but also causing confusion (Pacak et al., 1998). Selye defined stress as the nonspecific responses of the body to various noxious agents (the principle of nonspecificity). Among these responses, he particularly noted the triad of thymus involution, adrenal enlargement and formation of gastric ulcers. (However, he did not report the quantitative data of gastric ulcers in any his papers.) He gave various noxious stimuli (fasting, drug injections, surgical injuries, restraints, and so on) to rats, and reported the results in his paper (Selye, 1936b). However, he provided only raw data (thymus, and adrenal weights in individual rats), and did not perform any statistical analysis. It was not his fault because it was very common in that time. However, at present time it may be meaningful that someone analyzes his data (Selye, 1936b) statistically. In this study the results of such analyses are reported. Fortunately, since it was obtained from respective 6 rats in each group, statistical tests could be performed despite the small number of samples. All of the analyses in this paper were performed entirely based on the numerical values shown in the tables of Selye's paper (Selye, 1936b: Table I, II, and III). Independent analysis of variances (ANOVAs) and t-test were used. And U-test was also used.

\section{Results of Statistical Analyses}

\subsection{Fasting}

Selye initially evaluated the effects of fasting. The thymus weight clearly decreased along with fasting days (Figure 1: $\mathrm{F}_{4,25}=29.57, p<0.001$; 1-way independent ANOVA). In particular, marked atrophy was observed after fasting for 3 and 4 days (The mean thymus weights were less than $90 \mathrm{mg}$, being about $30 \%$ of the mean in the control group). However, the adrenal weight did not differ between the fasting and control groups (Figure 1: $\mathrm{F}_{4,25}=2.29, p=0.087$; $p$ s $>0.35$ by Dunnett's multiple comparison test).

The thymus weight decreased in the fasted groups compared with the control groups of 2, 3 and 5 month-old rats (Figure 2). As a result of 2-way independent ANOVA, the effect of fasting $\left(\mathrm{F}_{1,30}=50.32, p<0.001\right)$, and that of age (months) $\left(\mathrm{F}_{2,30}=14.03, p<0.001\right)$, which was commonly observed for thymus weight in this age
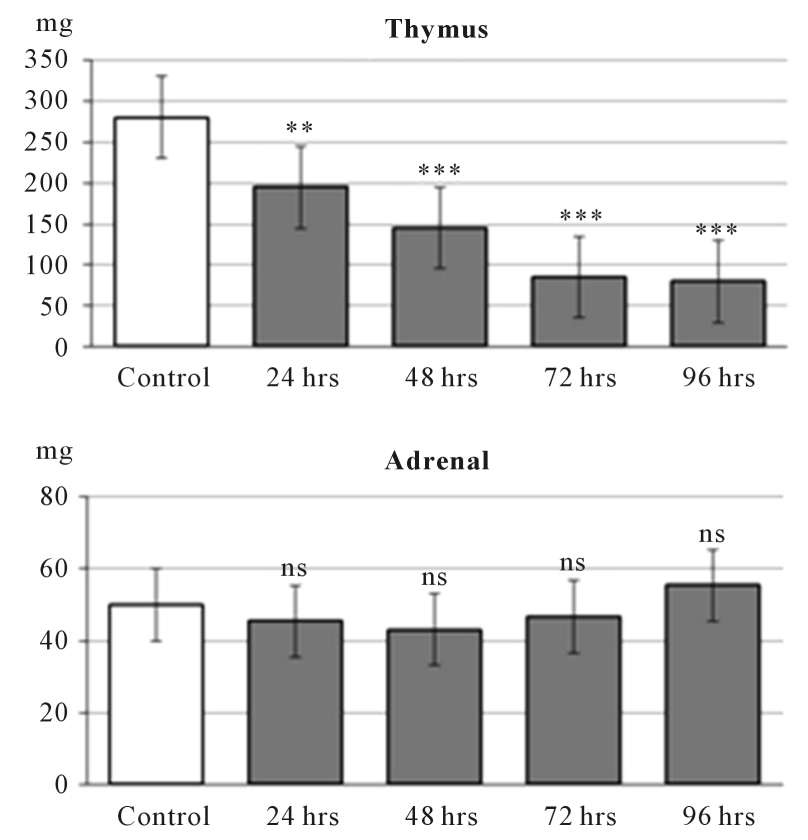

Figure 1. One, two, three or four days fastings (3-month-old rats). Thymus and adrenal weights were determined immediately after fasting for 0 (control), 24, 48, 72, or 96 hours (Selye, 1936b: p. 235). Each group consisted of 6 female rats aged 3 months. Error bars represent 95\% confidence intervals. (Results of Dunnett's tests between the control group and the respective fasting groups: $\left.{ }^{*} p<0.05,{ }^{* *} p<0.01,{ }^{* * *} p<0.001\right)$ All the figures and tables in this study were created entirely based on the numerical values shown in Selye's tables (Selye, 1936b: Tables I, II, and III). 

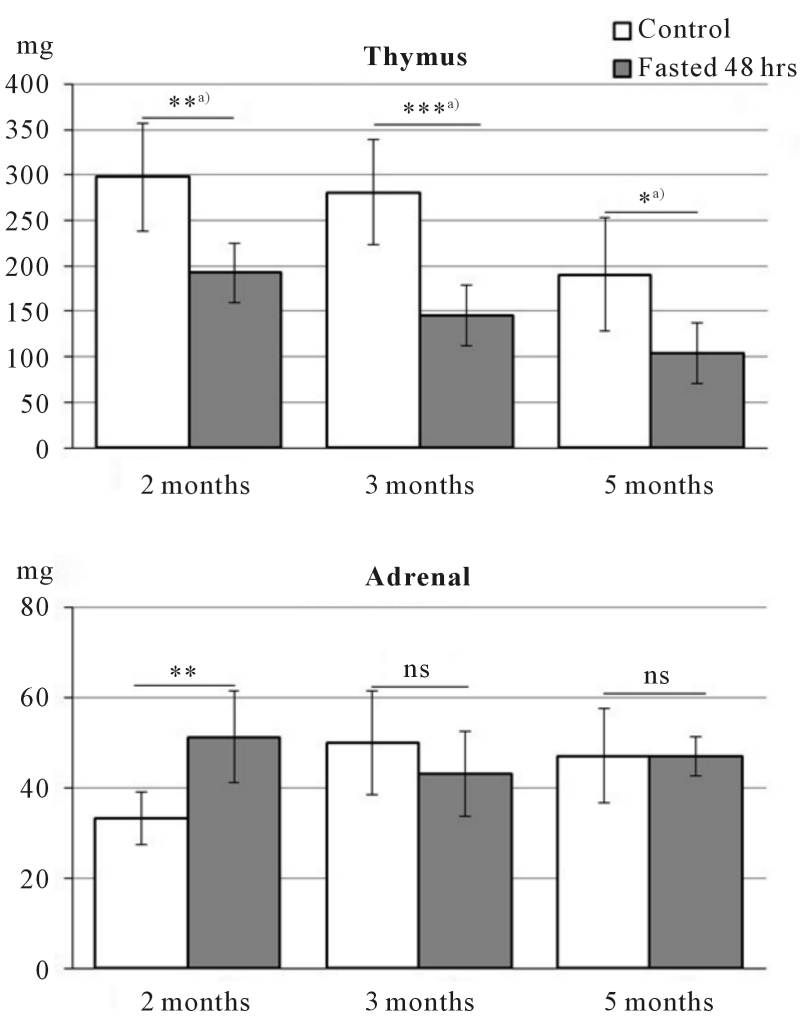

Figure 2. Two days fasting. Thymus and adrenal weights were determined immediately after fasting for 0 (control), or 48 hours. Both the fasting and non-fasting (control) groups consisted of six female rats aged 2, 3, or 5 months (Selye, $1936 \mathrm{~b}$ : Table I). Error bars represent 95\% confidence intervals. (Results of t-tests $(\mathrm{df}=10)$ between the fasting and control groups at each age: $\left.{ }^{*} p<0.05,{ }^{* *} p<0.01,{ }^{* * *} p<0.001\right)$. ${ }^{\text {a) }}$ These t-tests are only for refer, because AVOVA was performed and the interactions (fasting $\mathrm{x}$ age) did not reach any significance (please see the text).

range, were significant. But the fasting-age interaction was not significant $(p=0.44)$. As also shown in Figure 2, the adrenal weight was higher in the 2-month-old fasting group than in the corresponding control group, but did not differ between the 3- or 5-month-old fasting and control groups. As a result of 2-way independent ANOVA for the adrenal weight, only fasting-age interaction was significant $\left(\mathrm{F}_{2,30}=6.76, p=0.004\right)$. And these findings could be confirmed by t-tests (Figure 2). The main effect of fasting or age was not significant (fasting $p=0.21$, age $p=0.33$ ).

Thus, definite thymus involution was observed after fasting. However, adrenal enlargement was observed only in the 2-month-old group fasted for 48 hours, and absent in the all other fasting groups. It is worthy of note that no adrenal enlargement was observed even when the thymus weight decreased markedly.

\subsection{Drug Injections}

Selye subsequently evaluated the effects of atropine, formaldehyde, and morphine injections (Figure 3). Each drug reduced the thymus weight (Please see the results of t-tests shown in this figure). The adrenal weight was increased by atropine or formaldehyde, but not by morphine (Figure 3). In addition, the effects of adrenaline were evaluated in both 3- and 5-month-old rats (Figure 4). Adrenaline reduced the thymus weight and increased the adrenal weight (Table 1). There were 2 different patterns after drug injections, as was also observed after fasting. One pattern was the both occurrences of thymus involution and adrenal enlargement (atropine, formaldehyde, and adrenaline injections). The other was thymus involution without changes in the adrenal weight (morphine injection).

\subsection{Exposure to Cold}

Exposure to cold also reduced the thymus weight and increased the adrenal weight (Figure 4 and Table 1). 

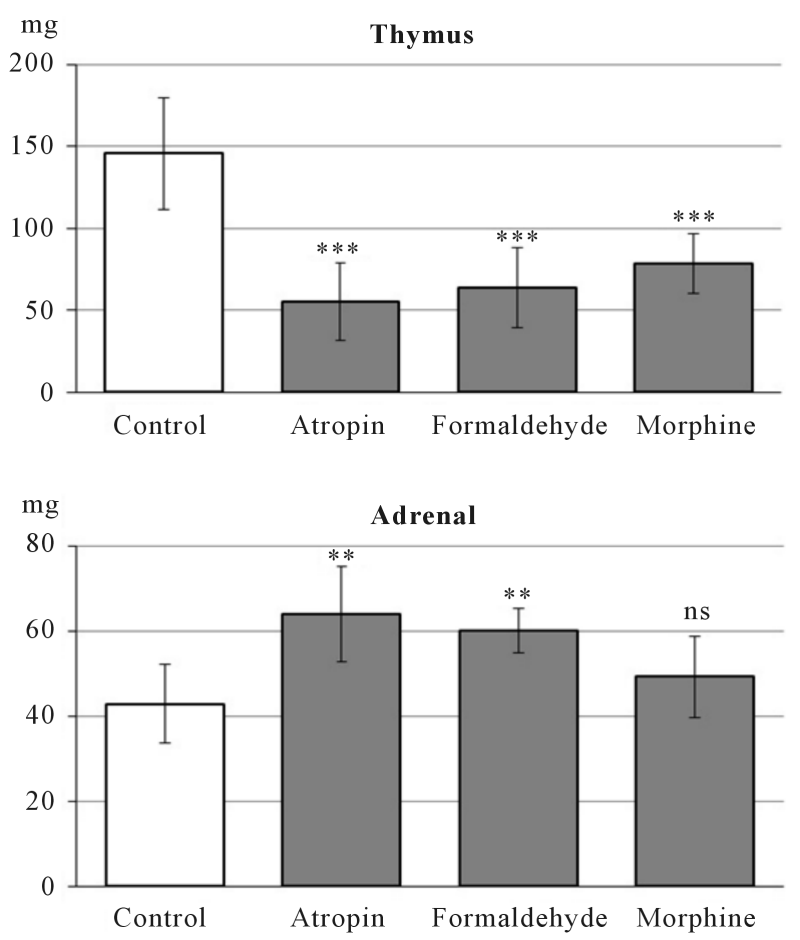

Figure 3. Atropine, formaldehyde, or morphine injections (3-month-old rats). Atropine (2 cc of $1 \%$ solution), formaldehyde ( 0.5 cc of $4 \%$ solution) or morphine ( 2 cc of $1 \%$ solution) was subcutaneously injected twice daily. The thymus and adrenal glands were weighed 48 hours after the first injection, and, therefore, all rats received a total of 4 injections (Selye, 1936b: p. 235). Selye stated: "all rats were fasted during the period, so as to avoid variations due to differences in the amount of food consumed.” (Selye, 1936b: p. 235). The control group was fasted for 48 hours without receiving any drug injection, and this group were the same as those presented in Figure 1. All rats were 3 months old females. Error bars represent $95 \%$ confidence intervals. (Results of t-tests $(\mathrm{df}=10)$ between the injections and control groups: ${ }^{*} p<0.05,{ }^{* *} p<0.01,{ }^{* * *} p<$ 0.001).

Table 1. Results of 2-way independent ANOVA (Group:experimental/control group x Age:the age of rats) performed on the thymus and adrenal weights (Figure 4). The degrees of freedom for the F ratio were 1 and 20 for every factor. ${ }^{a)}$ The homogeneity of variances was not verified (Levene's test). For it, U-test $(n 1=n 2=12$ ) was performed between the experimental and control groups at data combined 3 and 5 months-old aged rats. ${ }^{\text {b) }}$ The significant interaction (cold exposure-age)

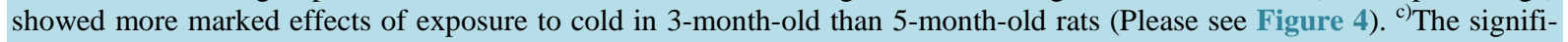
cant interaction (restraint-age) showed more marked effects of restraint in 3-month-old than 5-month-old rats (Please see Figure 4).

\begin{tabular}{ccccccc}
\hline & \multicolumn{3}{c}{ Thymus } & \multicolumn{2}{c}{ Adrenal } \\
\cline { 2 - 6 } Noxious stimuli & Group & Age & GXA & Group & Age & GXA \\
\hline Adrenaline & $p=0.002$ & $p=0.076$ & $\mathrm{~ns}$ & $p<0.5^{\text {a) }}$ & & ns \\
Exposure to cold & $p<0.001$ & $p<0.001$ & $\mathrm{~ns}$ & $p<0.001$ & $p .024^{\mathrm{b})}$ \\
Restraint (legs) & $p=0.005$ & $\mathrm{~ns}$ & $p=0.5^{\mathrm{c})}$ & $p<0.025^{\text {a) }}$ & & \\
\hline
\end{tabular}

\subsection{Restraints}

Restraint (legs) also reduced the thymus weight and increased the adrenal weight (Figure 4 and Table 1). In addition, Selye evaluated the effects of restraint using another restraint method (body) in 5-month-old rats (Figure 5). Using this method, the adrenal weight significantly increased while the thymus weight showed no significant change. This thymus result was contradicted with the above result of restraint (legs). However, the mean thymus weight in the restraint group was rather lower than that in the control group. Since the sample number was small 

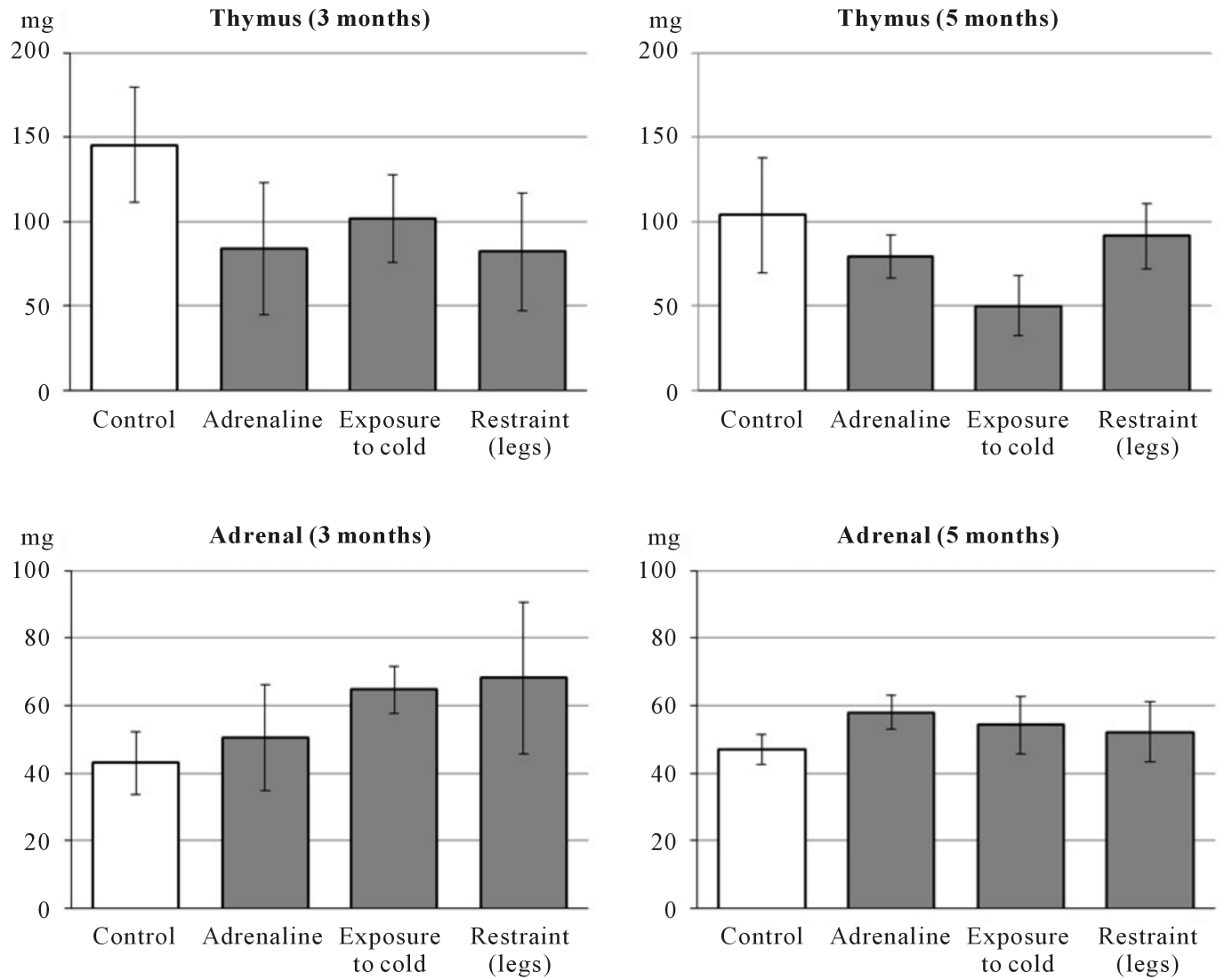

Figure 4. Adrenaline injections, exposure to cold, or restraint (legs). These were determined in both 3- and 5-month-old rats. Adrenaline was subcutaneously injected twice daily at a dose of 0.2 cc $(0.1 \%$ solution) in 3-month-old rats and 0.1 cc $(0.1 \%$ solution $)$ in 5 -month-old rats. The thymus and adrenal glands were weighed 48 hours after the first injection, and, therefore, all rats received a total of 4 injections (Selye, 1936b: p. 237). As exposure to cold, 3- and 5-month-old rats were kept in boxes at $5^{\circ} \mathrm{C}-7^{\circ} \mathrm{C}$ and $1^{\circ} \mathrm{C}-3^{\circ} \mathrm{C}$, respectively, for 48 hours. Restraint was performed by tying the legs together tightly for 48 hours (Selye, 1936b: p. 238). All rats were fasted for 48 hours and the controls were only fasted. Data of these control groups were the same as those presented in Figure 2. Error bars represent 95\% confidence intervals. The results of the statistical analyses were presented in Table 1.

( $\mathrm{n}=6$ per group), a significant change in the thymus weight may be observed with an increase in the sample number.

\subsection{Exposure to Heat}

Exposure to heat did not affect the thymus or adrenal weight (Figure 5).

\subsection{Three Types of Physical Injuries}

Three types of Physical injuries were made by Selye (Figure 6). Lesions called peritoneal injuries by Selye reduced the thymus weight and increased the adrenal weight. Extensive skin lesions decreased the thymus weight but did not change the adrenal weight. Bone fractures (fractures of the bilateral tibias and femurs) did not affect the thymus or adrenal weight. This finding was very surprising since the bone fractures are considered to be more noxious than the other physical injuries, or at least as noxious as them. Thus, it should be noted that there were two kinds of noxious stimuli (exposure to heat and bone fractures) that did not affect the thymus or adrenal weight.

\subsection{Body Weight}

Selye also reported the body weights of the individual rats. There is no consistent changes between the 

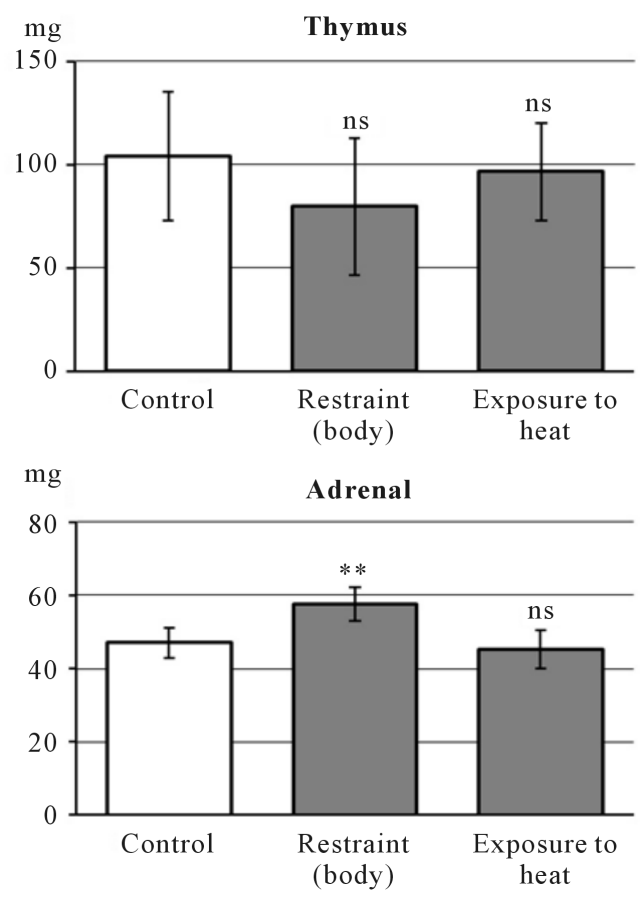

Figure 5. Restraint (body) or exposure to heat (5-month-old rats). Restraint (body) or exposure to heat was performed for 48 hours. For restraint (body), rats were wrapped tightly in a towel. For exposure to heat, rats were kept in a box at $35^{\circ} \mathrm{C}$ $40^{\circ} \mathrm{C}$ (Selye, 1936b: p. 238). The Data of control group were the same as those presented in Figure 2. Error bars represent $95 \%$ confidence intervals. (Results of t-tests $(\mathrm{df}=10)$ between the restraint or heat and control groups: ${ }^{*} p<0.05,{ }^{* * *} p<0.01$, $\left.{ }^{* * *} p<0.001\right)$.
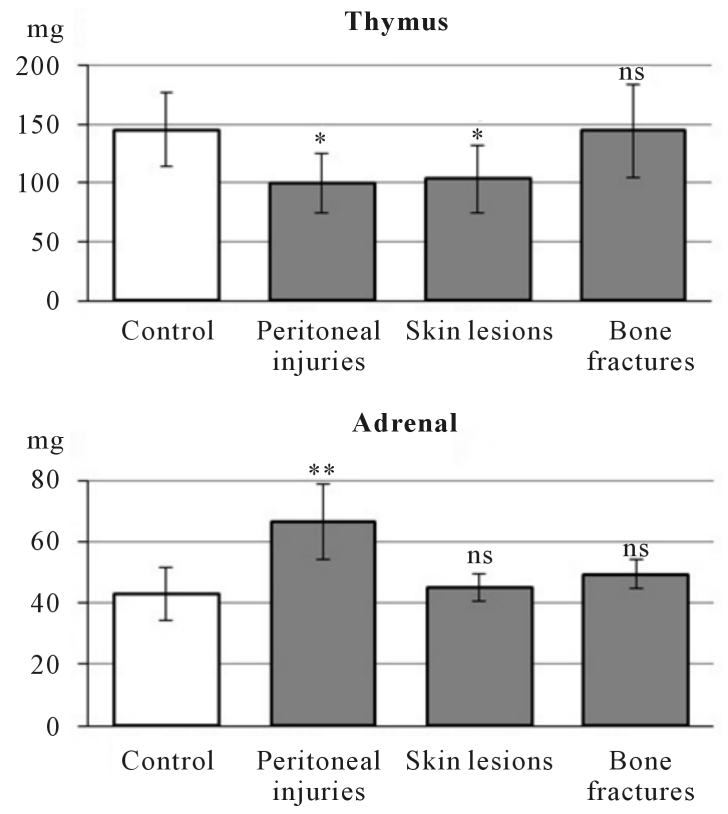

Figure 6. Three types of physical injuries (3-month-old rats). Peritoneal injuries ("All intestines were placed outside the peritoneal cavity for one minute."), extensive skin injuries ("The skin was detached from the subcutaneous tissues over large areas."), and bone fractures ("The tibia and femur were fractured under anesthesia on both sides.") were created (Selye, 1936b: p. 238). The thymus and adrenal glands were weighed 48 hours after the operations, and the rats were fasted until weighing. (The Data of control group were the same as those presented in Figure 1.) Error bars represent $95 \%$ confidence intervals. (Results of t-tests $(\mathrm{df}=10)$ between the respective injury groups and the control group: ${ }^{*} p<0.05,{ }^{* *} p<0.01,{ }^{* * * *} p<$ 0.001). 
experimental and control groups. Please see the tables of Selye's article (Selye, 1936b).

\section{Discussion}

The result pattern most frequently observed in Selye's data (Selye, 1936b) was thymus involution with adrenal enlargement. Although each group consisted of only 6 rats, significant differences were obtained under the many conditions (Table 2: 48-hour fasting in 2-month-old rats, atropine, formaldehyde, or adrenaline injections, exposure to cold, restraint (legs), and peritoneal injuries). These results very well confirmed Selye's claim and appeared to ensure Selye's stress theory (Selye, 1936a, 1936b). However, the second result pattern was thymus involution without changes in the adrenal weight. This pattern was observed under the several conditions (Table 2: fasting for 24 - 96 hours in 3-month-old rats, 48-hour fasting in 5-month-old rats, morphine injections, and skin lesions). The third pattern was the absence of changes in the thymus or adrenal weight. This pattern was observed under the two conditions (Table 2: bone fractures and exposure to heat). The second and third patterns were very incompatible with Selye's stress theory. Therefore, the author cannot avoid the conclusion that his stress theory of "nonspecificity" was disproved by his own experimental data.

These data were not marginal, because Selye stated "Owing to the great individual variations, particularly in thymus size, we had to draw our conclusions from averages of large experimental series, so that over 1500 rats were necessary to complete this work. It is impossible to report on each individual experiment without prolonging this paper unduly, and only representative, sample experiments, necessary to substantiate our conclusions, will be discussed." (Selye 1936b: p. 235). If it was true, the following description in the "Nature" letter (Selye, 1936a) was not right. Selye stated "Experiments on rats show that if the organism is severely damaged by acute nonspecific nocuous agents such as exposure to cold, surgical injury, ..., or intoxications with sublethal doses of diverse drugs (adrenaline, atropine, morphine, formaldehyde, etc.), a typical syndrome appears” (Selye, 1936a: p. 32). From a different point of view, it could be easily supposed that Selye did not propose his original stress theory (Selye, 1936a) if he had computed the averages of the rat groups.

Table 2. Summary of the statistical analyses.

\begin{tabular}{|c|c|c|c|c|}
\hline \multicolumn{2}{|c|}{ Noxious stimuli } & \multirow{2}{*}{$\begin{array}{c}\mathrm{Age}^{\mathrm{a}} \\
3\end{array}$} & \multirow{2}{*}{$\begin{array}{c}\text { Thymus Involution } \\
++++^{\text {b) }}\end{array}$} & \multirow{2}{*}{$\begin{array}{c}\text { Adrenal Enlargement } \\
\text {-_b) }\end{array}$} \\
\hline Fasting & 24, 48, 72 and 96 hrs & & & \\
\hline \multirow{5}{*}{ Injections } & $48 \mathrm{hrs}$ & 2 & ++ & ++ \\
\hline & $48 \mathrm{hrs}$ & 5 & + & - \\
\hline & Atropin & 3 & +++ & ++ \\
\hline & Formaldehyde & 3 & +++ & ++ \\
\hline & Morphine & 3 & +++ & - \\
\hline \multirow{3}{*}{ Exposure } & Adrenaline & $\begin{array}{l}3 \\
5\end{array}$ & $+^{\mathrm{b})}$ & $+^{c)}$ \\
\hline & Exposure to cold & $\begin{array}{l}3 \\
5\end{array}$ & +++ & $+++^{\text {b) }}$ \\
\hline & Exposure to heat & 5 & - & -- \\
\hline \multirow[t]{2}{*}{ Restraint } & Restraint (legs) & $\begin{array}{l}3 \\
5\end{array}$ & $+++^{\mathrm{b})}$ & $+^{\mathrm{c})}$ \\
\hline & Restraint (body) & 5 & $--^{d)}$ & ++ \\
\hline \multirow[t]{3}{*}{ Injuries } & Peritoneal injuries & 3 & + & ++ \\
\hline & Skin lesions & 3 & + & -- \\
\hline & Bone Fractures & 3 & -- & - \\
\hline
\end{tabular}

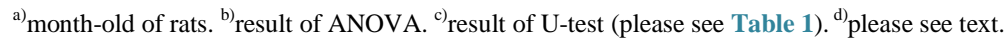


Several psychological researchers have already contradicted Selye's "the principle of nonspecificity" (Kemeny, 2003; Koolhaas et al., 2011; Mason, 1971; Pacak et al., 1998; Steptoe, 1983). Most of them measured novel responses (such as gene expressions or the plasma concentration of catecholamine) (Koolhaas et al., 2011; Kvetnansky, Pacak, Sabban, Kopin, \& Goldstein, 1997; Pacak et al., 1998) or employed new experimental conditions (Mason, 1971, see also McEwen, \& Lasley, 2002: pp. 47-49), or were theoretical consideration reviewing many experimental researches (Kemeny, 2003; Nageishi, 2013; Steptoe, 1983). The present analysis showed that Selye's stress theory (Selye, 1936a) was disproved by his own experimental data (Selye, 1936b), and therefore it would give the fairly foundations to those psychological articles.

In addition, thymus involution occurred under all conditions, but no adrenal enlargement was observed under the several conditions. In general, the hypothalamic pituitary adrenocortical (HPA) axis and sympathetic adrenomedullary (SAM) system are considered to be key players in stress responses (Koolhaas et al., 2011). However, based on the results of this analysis, when animals continuously receive noxious stimuli at least for a long period (48 hours), thymus involution indicating decreased immune activity may be a more inevitable response. As mentioned already, when thymus involution was present, even marked involution, there were two different results for the adrenal weight, i.e., significant enlargement and no changes. Mason $(1971,1975)$ also described that activity of the pituitary-adrenocortical system can increase, decrease, or remained unaffected in response to different stressors. The reason for these results is unclear at present. However, the following hypothesis can be formulated: When animals cope with noxious stimuli using active and behavioral strategies (such as flight or fight) (Canon, 1915), adrenal enlargement occurs. However, when animals cope with noxious stimuli using passive or covert strategies (such as freezing or enduring), no adrenal changes occur. Of course, this hypothesis should be tested. However, this result does not imply that activations of HPA and SAM are not induced immediately or shortly after the receiving of noxious stimuli (Canon, 1915).

Concerning the third result pattern, exposure to heat and bone fractures induced no changes in the thymus or adrenal weight. With an increase in the environmental temperature, rodents including rats, secrete actively saliva for maintaining the body temperature. When saliva is widely spread on the own body surface, the body temperature decreases due to its evaporative heat loss. Within the temperature range used by Selye $\left(35^{\circ} \mathrm{C}-40^{\circ} \mathrm{C}\right)$ (Selye, 1936b), rats may have maintained their temperature in an almost normal range (Hainsworth, 1967). In that case strong discomfort or fear would not be induced for the rats. On the other hand, there are great differences according to the type and severity of the fractures, although Selye did not clearly describe (Selye, 1936b). For example, complete fractures of the bilateral tibias and femurs cause profuse bleeding into the subcutaneous soft tissue, leading to death within a few hours in most animals. Therefore, in Selye's study it may be the most reasonable to consider that partial fractures were created by compression using such as forceps. When tibial and femoral fractures are created using such a method, gradual bleeding into the subcutaneous tissue may occur. When the rats awoke from anesthesia, blood flow to the brain may have been inadequate, and they may have felt negligible pain, resulting in no stress responses to these fractures. Therefore, these two interpretations revealed that the stress responses were not elicited if the psychological emotional reactions (e.g. discomfort, fear or pain) were not felt or induced, although animals received noxious stimuli. (These two interpretations were based on some speculations because Selye did not describe the physical conditions of the rats after the 48-hrs treatments.)

Under all the conditions excluding the above two, rats were hungry or had severe pain, fear, and anxiety (Imada \& Nageishi, 1982) throughout the 48 hours, or repeatedly felt nausea and abdominal discomfort (Nageishi, 2013). Under those conditions, these psychological factors would induce stress responses in the animals (Mason, 1971, 1975; Nageishi, 2013). Mason (1971) stated “Of the existing known bodily mechanisms which might be capable of such a 'non-specific' response to 'nocuous' stimuli, the psychological mechanisms of emotional arousal to threat seem to be ideally suited to the task." (p. 330). And also he stated "If this interpretation is correct, then the 'stress' concept should not be regarded primarily as a physiological concept but rather as a behavioral concept. The more correct basic conclusion really appears to be, then, that adrenal cortical responses occur in many different laboratory (experimental) situations involving a wide variety of stimuli, because emotional reactions (which elicit adrenal cortical responses) occur commonly in a wide variety of laboratory situations in which animals or humans are subjected to 'physical stress'.” (p. 331). The present author concludes that Selye’s experimental data themselves support above-cited Mason’s proposal (Mason, 1971, 1975) that all stress responses are elicited through psychological emotional reactions, although it had been contradicted by Selye himself (Selye, 1975). Moreover, those are very compatible with the recent psychological stress theories (Kemeny, 
2003; Koolhaas et al., 2011; Pacak et al., 1998; Steptoe, 1983).

\section{Acknowledgement}

I very thank Kozo Sugioka (Himeji Dokkyou University) for his advice and expertise.

\section{References}

Canon, W. (1915). Bodily Changes in Pain, Hunger, Fear and Rage, an Account of Recent Researches into the Function of Emotional Excitement. New York and London: D. Appleton and company. http://dx.doi.org/10.1037/10013-000

Hainsworth, F. R. (1967). Saliva Spreading, Activity, and Body Temperature Regulation in the Rat. American Journal of Physiology, 212, 1288-1292.

Imada, H., \& Nageishi, Y. (1982). The Concept of Uncertainty in Animal Experiments Using Aversive Stimulation. Psychological Bulletin, 91, 573-588. http://dx.doi.org/10.1037/0033-2909.91.3.573

Kemeny, M. E. (2003). The Psychobiology of Stress. Current Directions in Psychological Science, 12, 124-129. http://dx.doi.org/10.1111/1467-8721.01246

Koolhaas, J. M., Bartolomucci, A., Buwalda, B., de Boer, S. F., Flügge, G., Korte, S. M,, Meerlo, P., Murison, R., Olivier, B., Palanza, P., Richter-Levin, G., Sgoifo, A., Steimer, T., Stiedl, O., van Dijk, G., Wöhr, M., \& Fuchs, E. (2011). Stress Revised: A Critical Evaluation of the Stress Concept. Neuroscience and Biobehavioral Reviews, 35, 1291-1301. http://dx.doi.org/10.1016/j.neubiorev.2011.02.003

Kvetnansky, R., Pacak, K., Sabban, E. L., Kopin, I. J., \& Goldstein, D. S. (1997). Stressor Specificity of Peripheral Catecholaminergic Activation. Advances in Pharmacology, 42, 556-560. http://dx.doi.org/10.1016/S1054-3589(08)60811-X

Mason, J. W. (1971). A Reevaluation of the Concept of “Non-Specificity” in Stress Theory. Journal of Psychiatric Research, 8, 323-333. http://dx.doi.org/10.1016/0022-3956(71)90028-8

Mason, J. W. (1975). A Historical View of the Stress Field. Journal of Human Stress, 1, 6-12, 22-36. Http://Dx.Doi.Org/10.1080/0097840x.1975.9940405

McEwen, B., \& Lasley, E. N. (2002). The End of Stress as We Know It. Washington, DC: Joseph Henry Press.

Nageishi, Y. (2013). A Critical Review for Selye’s Stress Theory II: From the Viewpoint of Behavioral Science. Behavioral Science Research, 52, 47-56. (In Japanese with English abstract)

Pacak, K., Palkovits, M., Yadid, G., Kvetnansky, R., Kopin, I. J., \& Goldstein, D. S. (1998). Heterogeneous Neurochemical Responses to Different Stressors: A Test of Selye's Doctrine of Nonspecificity. American Journal of Physiology-Regulatory, Integrative and Comparative Physiology, 275, R1247-R1255.

Selye, H. A. (1936a). A Syndrome Produced by Diverse Nocuous Agents. Nature, 138, 32. http://dx.doi.org/10.1038/138032a0

Selye, H. A. (1936b). Thymus and Adrenals in the Response of the Organism to Injuries and Intoxications. British Journal of Experimental Pathology, 17, 234-248.

Selye, H. A. (1975). Confusion and Controversy in the Stress Field. Journal of Human Stress, 1, 37-44. http://dx.doi.org/10.1080/0097840X.1975.9940406

Steptoe, A. (1983). Stress, Helplessness and Control: The Implications of Laboratory Studies. Journal of Psychosomatic Research, 27, 361-367. http://dx.doi.org/10.1016/0022-3999(83)90067-3 